DOI: 10.1590/2316-4018387

\title{
Saer versus Aira: versões de uma antropologia especulativa
}

\author{
Antonio Marcos Pereira*
}

\section{1}

Na condição de leitor interessado nas produções de Juan José Saer e César Aira, bem como numa série de outros autores que terminam por consolidar uma constelação particular de interesses que, ao longo dos últimos anos, vão se apegando à minha própria imagem como produtor de discurso sobre literatura, venho observando uma reação, por parte de críticos e comentaristas de literatura, amigos, colegas, alunos, enfim, leitores de ficção contemporânea, que caminha mais ou menos assim. Saer, diz-se, é um representante de uma espécie de alto modernismo austral: é um autor sério, melancólico, participante dojogo de negociações específico da geração que viveu as ditaduras latino-americanas, o exílio, e as particularidades da perda, da expiação e do testemunho que são o ônus e legado de uma certa matriz de autores à qual, ainda que de maneira qualificada, Saer pertenceria. A obra em questão, além do mais, traz uma semelhança de família com o ciclo balzaquiano que, devidamente temperada pelas transformações das possibilidades narrativas que tiveram lugar ao longo do século XX, compõe uma espécie de saga arrevesada do Rio da Prata que ultrapassa em muito a comédia de costumes, avançando na exploração, por meios literários, do que seria a invenção da particularidade e da especificidade rioplatense. Saer, ainda, teria se esforçado metodicamente por elidir sua presença na construção de recepção aos seus objetos literários: quer ser alheio e ausentar-se do circuito midiático de exposição dos objetos literários. Sua produção e seu comportamento, sua performance de autor, em uma mescla de evitação, negatividade, melancolia e tragédia, lidam com problemas sobremaneira modernos: como narrar, como registrar o percebido, como discriminar as contribuições relativas dos supostos polos no jogo tradicional do conhecimento. Justamente por isso, suas manobras intertextuais verificam diálogos com Joyce, Faulkner, e com o Nouveau Roman, indicando uma dieta de referências que reforçam sua condição de autor, digamos, de disposições modernas.

Já no caso de César Aira estamos diante de outros quinhentos: para começo de conversa, são cinquenta livros, e essa produção exuberante,

\footnotetext{
* Professor Adjunto do Departamento de Letras Vernáculas da Universidade Federal da Bahia. Doutor em Estudos Linguísticos pela Universidade Federal de Minas Gerais (UFMG).

E-mail: antoniomarcospereira@gmail.com
} 
impressionante e transbordante é parte indissociável de sua assinatura, uma marca autoral imediata e inevitavelmente referida quando quer que o nome de Aira venha à conversa. Suas inúmeras novelinhas são, via de regra, acopladas a adjetivos que as qualificam como tresloucadas, desvairadas, nonsense, histórias que caminham adiante na base de um aparentemente indomável desejo de narrar, sempre eivadas de um componente lúdico, jocoso e leve que inclusive permite que seu narrador, na maior desfaçatez, antes as abandone que as resolva ou finalize. Aira não teme a acusação de falta de seriedade ou frivolidade: ao contrário, a celebra, e a verifica em situações de interlocução com leitores, notável disposição para um autor de sua idade, de sua geração. Elegendo para suas referências centrais Duchamp e jazzistas de vanguarda como Cecil Taylor, Aira com isso estabelece, implicitamente, um pacto com a audiência que enfatiza sua autoconsciência com relação à questão das membranas definidoras dos objetos artísticos e, por extensão, dos objetos literários. Por essa via, sua ficção se compatibiliza, com magnânima equanimidade, com aspectos centrais de um entendimento do presente, com os quais parece estar negociando claramente: a abundância de títulos já é parte de uma conversa, potencialmente satírica, com a demanda perene pelo novíssimo novo, e suas traquinagens com sua própria figura de autor - "La niña Aira" sendo talvez o mais comentado exemplo - seriam mais um aspecto a salientar que Aira, sim, é a bola da vez, o autor contemporâneo por excelência, capaz de se orientar com relação a aspectos de sua circunstância com precocidade e presciência, fazendo-se inclusive mais novo que aqueles que, cronologicamente, fariam mais jus ao título.

Esses comentários constituem uma espécie de nuvem de apontamentos, que mescla opiniões ligeiras a material de divulgação jornalística e ao histórico de recepção crítica dos autores, instituindo um sistema de balizas que se retroalimentam, e no senso-comum de certos setores do campo literário que tratam de tais autores e temas, essas linhas de recepção se consolidam como campos de força, atraindo magneticamente estruturas de confirmação e verificação. Assim é que, em um trabalho perspicaz, fruto evidente de uma leitura cuidadosamente situada de um romance de Saer, Lo imborrable (2003), Anália Gerbaudo (2006) indica não apenas que Saer se presta ao epíteto de "último modernista" como também sugere que sua própria leitura se quer "moderna". Fazendo uso de remissões a todo um campo de intérpretes de Saer, com distinções internas significativas - desde Dalmaroni e Merbilhaá (2000) até Kohan (2003), passando por Premat (2002) -, Gerbaudo inclina-se a favorecer a ideia de que há um imperativo, solicitado pelo próprio projeto estético de Saer, para ser lido 
"modernamente". Todavia, o procedimento que ca-racteriza o processo interpretativo de Gerbaudo não é, enquanto tal, tema-tizado: ler modernamente passa, assim, como sendo equalizável a ler de maneira cerrada, próxima ao texto, algo que constatamos por inferência uma vez que o regime de evidências ao qual a autora acorre é marcado pelo predomínio do texto do próprio Saer. Certamente não se trata de um recurso exclusivista ao "texto literário em si", pois a autora faz uso tanto da produção ensaística de Saer quanto de produções de autores - como Bourdieu - e intérpretes de literatura - como Sarlo - que ultrapassam o escopo do que poderíamos localizar como uma estratégia marcadamente anacrônica, passada, não contemporânea e, logo, "moderna", de crítica literária. Ainda, Gerbaudo se pergunta como lidar com especificidades do texto saeriano que poderiam ser tomadas como teste de resistência justamente da sua configuração como sendo, eminentemente, "modernos": Que nome dar a estes escritos que se definem como romances, mas que, de algum modo, jogam com nossas convenções a respeito do gênero (ou, pela mesma via, dos poemas que se propõem como "arte de narrar")? Como interpretar as teses sobre literatura vazadas por personagens da ficção em contraponto àquelas que aparecem na produção ensaística do autor? Gerbaudo tateia em torno dessas questões e as deixa no ar, como parte de seu horizonte de problemas, cabendo a nós acolhê-las como tipicamente modernas e, por extensão, eventualmente alheias a dimensões propriamente contemporâneas; à medida que ela avança, o que seria essa crítica moderna sugerida, enquanto procedimento específico, não se explicita, mas se indica como desejo e como horizonte de compatibilização necessário com o que haveria de modernista no autor examinado.

Pela mesma via, observamos que Sandra Contreras (2002), em seu conhecido e admirável estudo sinóptico da narrativa de Aira, já em seu movimento de abertura descreve o projeto de Aira como sendo o de construir-se, explícita e intencionalmente, enquanto uma alternativa à "estética e à ética da negatividade" presentes na narrativa saeriana, fazendo de si mesmo um "anti-Saer". Após elencar vários aspectos do procedimento de distinção que permite a Aira, em um momento inicial da carreira, numa operação de "beligerância estratégica" (Speranza, 2007), angular-se contra aqueles que se tornam talvez os dois nomes centrais da produção ficcional argentina após a ditadura, Piglia e Saer, Contreras indica que "é suficiente lembrar que à intransitividade da arte Saer jamais daria o nome de frivolidade, e o frívolo - tomado ao mesmo tempo como sendo falta de seriedade e índice da desimportância da obra - é o próprio signo da arte de Aira, de sua sensibilidade e de sua provocação" 
(Contreras, 2002, p. 30). Nesse mesmo pacote de considerações sobre o projeto de Aira, Contreras alude a seus vínculos com as vanguardas do início do século $X X$ e, a partir dessa conexão, a sua preocupação maior com o gesto e ação artísticos, com a configuração de um afazer que se justifica enquanto performance - e seu desprezo pela noção de que a arte encaminha uma experiência particular de produção de conhecimento, que eventualmente a justificaria. Nessa visada, se a arte produz principalmente mais arte e artistas, pela mesma conexão à literatura cumpre produzir, antes de mais nada, mais literatura e autores. Dinâmicas de produtividade em tese automatizáveis, que fazem uso de coisas já prontas (ready-made) e que, ao mesmo tempo, indicam uma astuta percepção da função da assinatura no jogo de constituição do mundo de objetos literários seriam os eixos de coordenação da obra de Aira, aspectos centrais da fatura do procedimento-Aira que a tudoécapaz de visitar sempre com soberbaironia, e nunca sendo capturado nas malhas da ingenuidade. Contreras alude à centralidade de um ensaio de Aira como uma espécie de declaração de princípios, uma ars poetica, seu "A nova escritura" (1998/2000). Nele, Aira afirma que "Os grandes artistas do século XX não são os que fizeram obra, mas aqueles que inventaram procedimentos para que a obra se fizesse sozinha, ou não se fizesse. Para que precisamos de obras? Quem quer outro romance, outro quadro, outra sinfonia? Como se já não existissem o bastante!" (Aira, 2007, p. 13). Certamente, trata-se de manifesto a ser lido de viés, com ironia, sem ingenuidade: vem de um autor que produziu dezenas de narrativas curtas, que já construiu uma obra e que, por via da contrafação de sua própria persona enquanto Autor, seja de ensaio, seja de ficção, mantém-se fiel a seu próprio imperativo de frivolidade e, portanto, não pode ser levado totalmente a sério.

Obviamente, exagero, mas só um pouco: o que me parece digno de nota aqui é que, considerando todo seu esforço sistemático para dialogar com a produção de Aira, para conferir-lhe um sentido - ou seja: para interpretála - Contreras não parece sentir-se solicitada a qualquer modificação em seu modus operandi enquanto crítica para atender à especificidade de seu objeto. Não há, assim, qualquer frivolidade no trato com a matéria textual supostamente frívola observada, e as regras do jogo crítico colocadas em pauta assemelham-se consideravelmente àquelas que, para tratar de Saer, Gerbaudo parecia definir como peculiarmente "modernas". Se esses autores são recebidos a partir de configurações estabelecidas a respeito de como lê-los, e se um é tratado como modernista derradeiro e outro como vanguardista contemporâneo, isso não parece trazer implicações diretas para o repertório de procedimentos de seus críticos, malgrado a denomi- 
nação que esses críticos dão ao que fazem. Se, por um lado, Gerbaudo dizia fazer uma leitura moderna de um autor modernista tomando seus parâmetros como dados, sem se propor a estabelecer qual a especificidade dessa leitura moderna, Contreras dá cabo de sua leitura de um autor vanguardista sem que com isso se implique em alterar os imperativos hermenêuticos de ocasião: a partir de um padrão de saliências que discerne na produção do autor escrutinado, Contreras avança integrando esse discernimento a outros eixos reforçadores, oriundos tanto da produção ensaística do autor quanto dos esforços interpretativos de outros críticos e teóricos da literatura e da cultura. Sua leitura de Aira é, aparentemente, tão "moderna" quanto a que Gerbaudo faz de Saer: perguntas aplicadas por Gerbaudo a dimensões da produção saeriana poderiam ser instaladas como interpelação à produção de Aira quase sem tirar nem pôr - questões como "Que nome dar a estes escritos que se definem como romances (ou, vá lá, "romancinhos" / "novelitas") mas que, de algum modo, jogam com nossas convenções a respeito do gênero? Como interpretar teses sobre literatura vazadas por personagens da ficção em contraponto àquelas que aparecem na produção ensaística do autor?"

\section{2}

O que temos aqui, então? Duas matrizes de recepção que, evidentemente, não são gratuitas, mas sim fruto de uma relação no mínimo dialógica, pautada por características do efeito de cada autor e cada projeto sobre suas condições de legibilidade e seus intérpretes. Assim, Saer e Aira aparecem aqui como instâncias reveladoras de orientações distintas no que diz respeito à questão da "História do Presente": um menos, outro mais contemporâneo; um negativo, sisudo e moderno, outro pura jocosidade, ironia e atualidade. Um dos intérpretes que examinamos sugere um modo moderno de leitura consoante com o projeto do Autor, convidando assim a uma interrogação sobre os procedimentos do crítico e sua eventual conexão com os do objeto observado. E essa interrogação, por sua vez, nos lembra que as balizas de observação e implicação que instituímos e utilizamos em nossas relações com os objetos literários são tão "inventadas" quantos os próprios textos examinados enquanto literatura e produzidos enquanto crítica - o que nos conduz a problematizar também os dispositivos utilizados para ler o Autor que, nessa diagramação que estamos explorando, nunca leva a culpa de ser "moderno".

Por essa via, talvez fosse interessante observar como, na recepção de Saer, ao evocar-se sistematicamente sua melancolia e negatividade há 
uma elisão igualmente sistemática de uma folga lúdica que, via de regra, se instala e reitera nas relações entre os personagens. Embora se apresentem de maneira menos saliente que os traços trágicos constitutivos de personagens e tramas que saltam aos olhos na leitura de seus textos, essas entradas cômicas são constitutivas dos jogos que justificam laços fundamentais entre os personagens, e formam oportunidades e saídas para a redescrição de eventos centrais nas tramas, que por essa via tendem a se manifestar antes em sua potência plástica e mutável que como matéria de rigorosa e absoluta definição. Mas, claro, a valorização de tais aspectos não se presta com facilidade à inserção no molde de recepção já pronto para o autor e, com isso, não é de se estranhar que passem ao largo da abordagem crítica menos minuciosa, pois dar conta delas demanda um trabalho que opere a partir de uma dialética comédia/tragédia, o que há de ser mais laborioso que a assunção de uma tonalidade negativa na obra como um dado. Ainda, a ênfase no local, "lugar", "zona", talvez rendesse melhor ao ser lida em contraponto à elisão de atributos que Saer sugere como uma espécie de antídoto para a má literatura: poderia, assim, ser lida como tática programática de inserção de seu próprio e peculiar olhar oblíquo num jogo que, à época, e ainda hoje, prima por celebrar uma conexão necessária entre a suposta autenticidade e a autoridade na construção do saber e do sabor local.

Da mesma maneira, considerando inclusive, como um aspecto incontornável do problema, a vastidão de itens em sua produção, ao caracterizarmos a poética de Aira como marcada pelo desvario, pelo nonsense e pela dissipação, tendemos a secundarizar textos que convocam o autoexame da experiência cotidiana, bem como a trama intertextual aí construída com autores tão pouco contemporâneos como Stendhal e Descartes. Ainda que sempre atravessados por táticas autoficcionais de representação, há uma intensificação do aparato intertextual mobilizado e uma considerável alteração do panorama emocional dos textos, que cedem lugar a um pathos que passa longe do dada e evoca a transitoriedade, a impermanência, a desilusão e a perda - temário bem pouco frívolo.

É em situações como essas que vemos como as estruturas de recepção, com tudo que tem de necessários propiciadores didáticos, trazem consigo também, implicitamente, interdições à leitura ou, para manobrar uma terminologia mais branda, marcadores do que é necessário observar nos autores e textos com os quais lidamos. Isso permite, por exemplo, que um leitor tão arguto e criterioso quanto Premat aproxime-se de Aira hipertrofiando o componente supostamente frívolo e vão de Cumpleaños (Aira, 2001) e, na mesma medida, afastando-se da própria possibilidade de 
acolhimento da narrativa como candidata a alguma forma de seriedade, tomando-o como apenas mais uma instância do "procedimento Aira", que é, "antes de tudo, uma perspectiva: são as andanças de um idiota no mundo da peripécia" (Premat, 2009, p. 245). O ponto final e, portanto, a condição contemporânea da série de invenções de autor que constitui os nós da trama proposta por Premat para a compreensão da literatura argentina no século XX seria esse filho tardio, idiota da família, "um monstro, um estrangeiro ou um selvagem". No limiar está aqui a condição de aprisionamento do projeto a balizas de recepção que o próprio autor contribui, dentro e fora da ficção, para fixar, condição que só pode ser ultrapassada pela manobra, talvez à primeira vista demasiado modesta, da insistência na leitura, mesmo no caso de um projeto que parece trabalhar insistentemente contra a possibilidade de ser lido por completo (o que, por sua vez, constitui outra instalação particular da recepção, com suas consequências já mencionadas - pois é um absurdo patente proclamar que é impossível ler todo o Aira).

Procurando investir um pouco mais nessa linha de exploração, ao examinar objetos ficcionais como La pesquisa (Saer, 1994) e Parmênides (Aira, 2006), encontramos solicitações do suposto fato histórico bastante interessantes, uma vez que levá-las a sério pode conduzir a pôr em xeque essas consumições estabilizadas da recepção. Veja-se, por exemplo, que o problema de atribuição de autoria descrito em La pesquisa passa por um retorno a uma narrativa que reapresenta e, assim, atualiza, a própria fonte da narrativa ocidental, a Ilíada. O dactilograma que aparece entre os pertences de Washington como um "inédito alheio", e que resulta em especulações de decifração da autoria que emulam, em outro patamar, as discussões sobre a autoria dos crimes narrados por Pichón, faz revolver e, portanto, reduzir a estabilidade, dessa que é uma das narrativas-matriz de nosso próprio entendimento do objeto literário. E mais: tal recondução é feita não com um telos afirmativo peremptório, mas sim a partir da exposição de uma lógica da suplementaridade entre verdades da experiência e verdades da ficção, instanciadas respectivamente nas figurações do Soldado Velho e do Soldado Jovem e reiteradas na maneira como, ao fim e ao cabo, a narrativa que supostamente resolve a trama é redescrita por Tomatis. Há, creio, bastante aí para nutrir um argumento que alojaria Saer, a partir dessa discussão, em um patamar que pressupõe sua disposição em tomar a facticidade histórica cum grano salis, e a reconhecer que - com as devidas benesses da ironia ressaltada pelo mise en abyme do romance como um todo - qualquer matéria de narração é sempre, necessariamente, matéria potencial de redescrição. Ironia pós-moderna e revisionismo po- 
tencial, em Saer? Saer, fazendo brincadeirinhas com Homero? Como se não fosse suficiente, essa matéria se expande, vazando para uma narrativa breve coletada em El lugar (2000), "En línea", conto que, aparentemente alegorizando a textualidade que abarca tanto os soldados gregos quanto Tomatis, Pinchón e, também, como peças do mesmo jogo, Autor e Leitor, termina na dispersão imaterial de um encantamento, na visão da dissolução de todas as coisas na mesma matriz de imponderáveis que começam e terminam enquanto texto. "Il n'y a pas de hors-texte" por Saer? Que espécie de "moderno" é, então, Saer?

No caso de Aira, sua conexão com a genealogia da literatura é ainda mais arrevesada, e justamente por isso mais expressiva, em particular considerando-se um autor de quem se habituou a esperar a frivolidade: em Parménides seu recurso genealógico não está na obra fundacional do material literário, mas sim naquilo que talvez se constitua no Outro discursivo mais evidentemente embaraçado com o material ficcional, o discurso filosófico. Ao abordar um suposto grau zero da matéria filosófica, Aira o faz com a habitual jocosidade, exibindo um Parmênides que nada escreve, que é pura oralidade e, além disso, é apenas um desejo de Autor, um reclame por uma assinatura. O texto, aquilo que se vinculará à sua assinatura constituindo, por essa via, sua ambicionada condição de Autor, Parmênides não tem, mas não se faz disso tampouco um problema, justamente pela presença daquele que, malgrado o título, é o efetivo protagonista da narrativa, Perinola. Este, sim, escreve, mas não é nada, e se foi um candidato a poeta e Autor, agora é um ghost writer do mundo antigo, que se faz assalariado de Parmênides e, a partir de uma procrastinação que mescla o sossego material oriundo do trabalho pago com o desassossego por sua perene interrogação da própria potência como produtor de um texto que está sempre adiante, sempre no porvir, e que em última instância nunca será seu, encontra sua derrocada justo no momento em que celebra a graça com que produziu algo: seu final se dá por força de seu encontro com "o presente". No texto que produz, que irá ser atribuído a Parmênides, e que inaugurará uma tradição de produções textuais que não são exatamente ficcionais nem necessariamente factuais, mas que ambicionam sistematicamente a valor de Verdade, a marca maior está no arbítrio que constrói o mundo a partir de substâncias fundamentais que se articulam em uma coreografia própria, essencial, necessária e incontornável. Mas a contrafação maior desse ensaio de mundo é "o presente", que mostra sua face como "uma fera turbulenta que solta rugidos incompreensíveis e escapa em todas as direções" (Aira, 2006, p. 125). Explorando o que Perinola haveria pensado no final desse último dia, tão impor- 
tante em sua vida, no qual enfim escreve o livro, que será de Parmênides, e no qual também se encontra com o presente e, com isso, com sua própria morte, Aira, em uma decolagem ensaística interna à narrativa, perguntase:

Quem poderá dizer o que pensou um outro, se dizer o que cada um pensou já é tão difícil? O que se pode fazer de melhor é reconstruir o pensamento a partir dos feitos posteriores, sempre e quando tais feitos tenham sido registrados. Claro que a reconstrução se baseia na suposição de que os feitos tenham obedecido a intenções formuladas no pensamento anterior, o que sempre é duvidoso e sujeito a acidentes. E o registro dos feitos é sempre lacunar e ambíguo. Tratando-se de um escritor, os "feitos" e o "registro" são a mesma coisa, com o que se evita o inconveniente do incompleto, mas se agiganta o da ambiguidade. A reconstrução dos pensamentos pertence à ordem da ficção, embora devêssemos despojar a ficção, neste caso, de suas conotações de invenção caprichosa, e vê-la antes como uma classe especial de trabalho filológico. (Aira, 2006, p. 114) (tradução minha)

\section{3}

Ora, capturar essa investida como frívola só pode resultar de um automatismo, um chute, uma espécie de reflexo patelar hermenêutico: nem é preciso muito boa vontade para confirmar que nesse trecho o narrador está problematizando seu próprio trabalho como ficcionista e, mais, sugerindo que essa tarefa seja objeto de redescrição e revisão - despojar a coisa da conotação de "invenção caprichosa", conceder-lhe a condição de uma "classe especial de trabalho filológico". Ainda, caberia observar como aqui Aira parece estar em insuspeita sintonia com Saer e sua sugestão de compreendermos a produção ficcional pela via da "antropologia especulativa". Em conhecido ensaio, depois de distribuir golpes a torto e a direito, atingindo no caminho a biografia literária, Umberto Eco e até Soljenitsin - o que, vejam bem, permite matizar bastante uma relação de alinhamento com o discurso do testemunho -, Saer valoriza as Ficciones de Borges dizendo que ali Borges "não reivindica o falso nem o verdadeiro enquanto opostos que se excluem, mas sim como conceitos problemáticos que encarnam a principal razão de ser da ficção". E continua:

Por causa deste aspecto crucial do relato fictício, e também por causa de suas intenções, de sua resolução prática, da posição singular de seu autor entre os imperativos de um saber objetivo e as 
turbulências da subjetividade, podemos definir de modo global a ficção como uma antropologia especulativa. (Saer, 1997, p. 16) (tradução minha)

"Uma classe especial de trabalho filológico", "uma antropologia especulativa": observem como essas sugestões, lançadas de chofre, vazadas em ficção e ensaio, e privadas de maiores elaborações a posteriori por seus autores, parecem rentáveis para o exame dos próprios feitos revisionistas desses autores com relação às supostas matrizes da narração e da especulação no Ocidente. Em Saer, os relatos homéricos são construídos no espaço necessariamente híbrido entre uma factidade comezinha (o Soldado Velho) e sua expansão e disseminação legendárias no momento mesmo de sua suposta ocorrência (o Soldado Novo), fazendo com que desde o grau zero a condição de tais relatos seja marcada pela mescla e pela irresolução. Em Aira, o texto filosófico fundacional por excelência, comumente tomado como a própria inauguração do discurso filosófico no Ocidente, aparece como um divertimento poético eventual, contraface de um presente que nada tem de necessário e que, em sua hostilidade potencial com relação a tudo que não seja contingente, termina por dar cabo de um autor que sequer é consignado pela história das ideias como o criador e possuidor do direito de assinatura no poema que concebeu.

Ora: o que devemos levar a sério nessas sugestões de Saer e Aira? O que devemos descartar como adventício e colateral? Lidar com essas questões nos conduz a considerar não apenas uma problematização das fronteiras ensaio/ficção como oportuna (no mínimo considerando-se o que o Autor diz em modo ficção vale do mesmo jeito que o dito em modo ensaio), mas também em reconhecer, mais uma vez, a complexidade das tarefas de taxonomia e avaliação literária que consignam a um dado autor um determinado lugar e natureza e, por essa via, angulam as formas de ler disponíveis para cada caso. Se acreditamos que tem algum valor o exame da ficção como problema, talvez seja cabível igualmente investigar as tramas que dizem respeito à composição da ficção como actante em um jogo específico no qual se movimenta também, evidentemente, a crítica. Assim, partindo dos casos de Saer e Aira, busquei promover um tensionamento agonístico do trabalho de recepção e comentário, operando com uma certa medida de "beligerância estratégica" que contribua para que algo da ordem do presente da prática crítica se faça ver, em sua eventual fragilidade especulativa, considerando o risco e a aposta que produzem seu continuado interesse e seu caráter de problema. 


\section{Referências bibliográficas}

AIRA, César (2001). Cumpleaños. Buenos Aires: Mondadori. (2006). Parménides. Buenos Aires: Mondadori.

(2007). Pequeno manual de procedimentos. Curitiba: Arte \& Letra.

CONTRERAS, Sandra (2002). Las vueltas de César Aira. Rosario: Beatriz Viterbo.

DALMARONI, Miguel e MERBILHAÁ, M. (2000). “Un azar convertido en don: Juan José Saer y el relato de la percepción". In: JITRIK, Noé (2000). Historia crítica de la literatura argentina. Buenos Aires: Emecé. v. 11.

GERBAUDO, Analia (2006). "Por una lectura moderna del último modernista". Astrolabio. n. 3. Disponível em: <http://www.astrolabio.unc.edu.ar/articulos/nuevosfrutos/articulos/gerbaudo.php>. Acesso em: 10 de março de 2009.

KOHAN, Martin (2003). “Dos recientes lecturas modernas”. Boletín. n. 11, p. 81-4.

PREMAT, J. (2002). La dicha de saturno: escritura y melancolía en la obra de Juan José Saer. Rosario: Beatriz Viterbo.

(2009). Héroes sin atributos. Buenos Aires: Fondo de Cultura Económica.

SAER, Juan José (1994). La pesquisa. Buenos Aires: Seix Barral. (1997). El concepto de ficción. Buenos Aires: Seix Barral. (2000). El lugar. Madri: El Aleph. (2001). Cuentos completos, 1957-2000. Buenos Aires: Seix Barral. (2003). Lo imborrable. 2. ed. Buenos Aires: Seix Barral.

SPERANZA, Graciela (2007). Fuera de campo. Buenos Aires: Anagrama.

Recebido em maio de 2011.

Aprovado em julho de 2011.

\section{resumolabstract}

\section{Saer versus Aira: versões de uma antropologia especulativa}

Antonio Marcos Pereira

O artigo propõe um confronto do trabalho de dois autores, Juan José Saer e César Aira, marcadamente distintos no que diz respeito às estruturas de recepção convocadas por suas obras, e que podemos traduzir particularmente na maneira como é percebida a relação de cada um com "o contemporâneo", o que resulta em seu alojamento específico em certas genealogias e na produção de suas respectivas inscrições na história literária latino-americana recente, aqui instanciadas em trabalhos de Anália Gerbaudo e Sandra Contreras. O exame de objetos ficcionais 
como La pesquisa, de Saer, e Parmênides, de Aira, nos leva a encontrar solicitações ambivalentes do fato supostamente histórico e de sua relação com a ficção, que são aqui apresentadas como oportunidades para operar criticamente com relação a estruturas estabelecidas de recepção e crítica do trabalho dos autores.

Palavras-chave: Aira, Saer, crítica

\section{Saer versus Aira: versions of a speculative anthropology}

Antonio Marcos Pereira

The paper proposes a confrontation of the work of two authors, Juan José Saer and César Aira, markedly different in the structures of reception their works bring forth, and that we might translate particularly in the way their relationship with "the contemporary" is perceived, resulting in specific placings in certain genealogies and in the production of their respective inscriptions in recent literary history in Latin America. The examination of fictional objects such as Saer's La pesquisa and Aira's Parmenides leads one to find ambivalent solicitations of the allegedly historical fact and its relation to fiction that are hereby presented as oportunities to operate critically towards the structures of established reception and criticism of the work of both authors.

Key words: Aira, Saer, critic

Antonio Marcos Pereira - "Saer versus Aira: versões de uma antropologia especulativa". Estudos de Literatura Brasileira Contemporânea, n. 38. Brasília, julho-dezembro de 2011, p. 109120. 